\title{
Detention Reservoirs as a Flood Control Measure
}

\section{P. Hettiarachchi}

\begin{abstract}
Employing detention reservoirs for mitigating floods is a widely applied strategy, all over the world. This is suitable for small urban drainage systems as well as for large fluvial flood protection schemes. This technique is mostly applicable for the urban areas where construction of flood bunds is restricted due to high value of properties to be removed.
\end{abstract}

Detention reservoir can be located within the area to be protected or somewhere upstream with low population density and low economic value. This will not only protect the area to be protected from flooding but also provide facilities for water based recreational activities, an attractive feature of modern cities. Further, it is a sustainable and low cost approach, free of adverse effects such as land subsidence, depletion of ground water etc.

This paper will discuss how this technique could be applied for the protection of cities located in flood plains of major rivers of our country.

\section{Introduction}

Flood hazards of our country have increased, drastically, in recent history due to urbanization and population growth. Frequency of high intensity rainfalls is also increasing due to climate change. For example, Sri Lankan commercial capital, Colombo city experienced two extreme storm events (494 $\mathrm{mm}$ in 18 hours and $440 \mathrm{~mm}$ in 9 hours) within 18 years (in 1992 and 2010). Both events exceed 100 year frequency rainfall according to our classification (based on the frequency analysis of past records) and such high intensity rainfalls had not been observed before. More than 100,000 families were affected by the recent flood in last November.

Even though it is difficult to develop flood control facilities to cope with such big events, it has to be realized that adopting some kind of protective measures to minimize the damages are a paramount necessity. Some of the following alternatives, depending on geographical and socio-economic features of the area, can be adopted in mitigating such hazards.

\section{Alternative Flood Control Measures}

i. Diversion of surplus water from the upper catchment to adjacent basins (trans-basin diversion). ii. Reduction of surface runoff by changing the land use pattern in the upper catchment (watershed management).

iii. Increase of drainage capacities by enlarging (widening and/or deepening) river channels where ever necessary.

iv. Introduction of early warning system and timely evacuation of people and valuables from the flood prone areas.

v. Construction of by-pass canals to divert peak flows in alternative paths.

vi. Construction of multi- purpose storage reservoirs

vii. Construction of detention reservoirs for temporary storage and controlled release of floodwater.

Combination of several alternatives mentioned above may be more appropriate for a particular case. The last option will be widely discussed in this paper since this seems a new approach, most appropriate for the urban areas of our country. Converting this to a multipurpose reservoir option will make it

Eng. Mrs. P. Hettiarachchi, B Sc. Eng, C. Eng.,

MIE (Sri Lanka, , M Sc. Hydrology, 
possible to address some other crucial problems such as irrigation, water supply, power production etc. Single purpose (flood detention only) reservoir is more suitable for low lying areas where providing a potential head required for hydropower or irrigation is not possible. However, this can be combined with some other purposes such as inland fishing, recreation, nature preserving etc.

Construction costs can be minimized by selecting suitable natural geographic formations such as natural lakes and marshy lands which can easily be converted to detention ponds.

\section{Types of Flood Detention Reservoirs}

There are two distinct types of flood detention reservoirs called 'on stream' and 'off stream', depending on the location of the reservoir relative to the stream, as illustrated in the Figure I. In an 'on stream' reservoir, dry weather flow passes through the storage area where as in 'off stream' reservoir dry weather flow by-passes the storage area.

Further classification is possible depending on whether the storage area is free of water during dry weather conditions (dry reservoir) or has a permanent pool (wet reservoir). An intermediate case (wet \& dry reservoir) is also possible where the permanent pool is much smaller than the total area available for storage. The last type is most appropriate for many of the cases having rapid inflows requiring vast areas for temporary detention.

For an 'off stream' reservoir, at least two flow control structures are required at the points of inflow to the reservoir and at the outlet of the reservoir. Those intakes and outlets may either be weirs or control gates depending on the capacities required and the topography of the area.

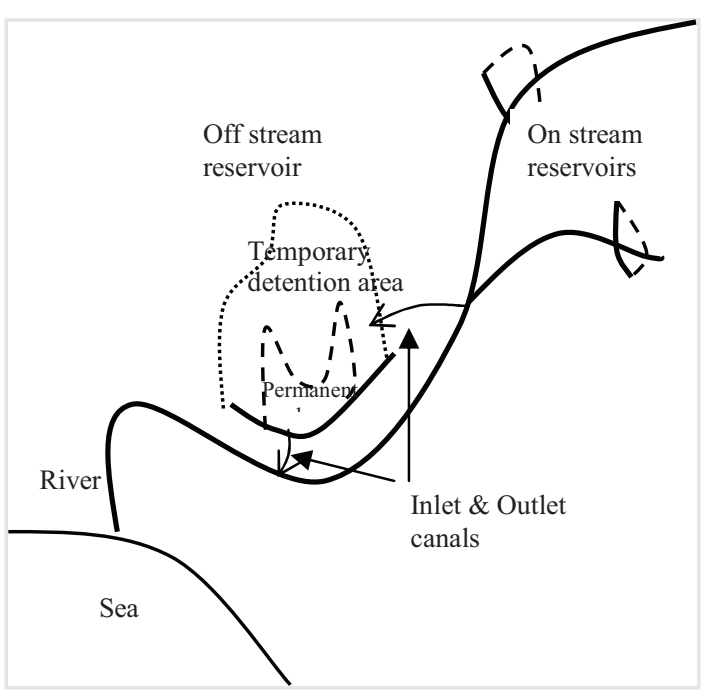

Figure 1-Two Types of Flood Detention Reservoirs

\section{How it Functions}

Whatever the type of the reservoir it has to be discharged to a natural stream, artificial canal or directly to sea after retaining flood water for some specified period until the storm ceases or the flood peak passes the area. In an on-stream reservoir water enters the reservoir, through natural water ways while in the other type water may enter from the river through a control gate, weir or a spillway. Outlet may be a weir or control gate in both cases.

When there is a controlled outlet, the operator may vary the gate opening so that during rising limb of inflow hydrograph, the outflow will match the inflow until the capacity of the downstream channel is reached (see Figure 2). Thereafter the gate may be used to maintain the outflow (not exceeding downstream canal capacity) while excess water is taken into storage until the inflow reaches its peak. On the recession side of the inflow hydrograph the same outflow (capacity of downstream canal) may be maintained in order to evacuate storage as quickly as possible. The outflow may be reduced to its dry weather value once the inflow has reduced to its base flow level. 


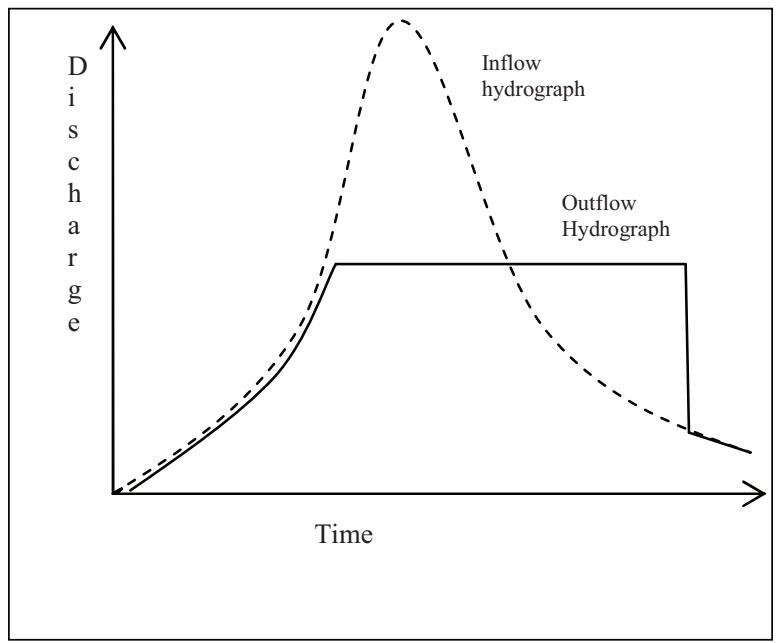

Figure 2 - Function of Detention Basin

\section{The Design Considerations of Flood Detention Basin}

In the preliminary stage of design, the designer has to study the topography, soils, land use, flow characteristics, flood frequencies and other relevant socio economic factors in order to select most appropriate flood control measure for a particular area or river basin. If flood detention reservoir is most appropriate, the designer must go for the hydrological design phase which involves generation of inflow hydrographs and routing them through proposed reservoirs etc. so as evaluate the performance of the entire detention (or retarding) basin. Contour survey of detention basin is necessary in this step. Once the time lag between inflow and outflow peaks and the degree of attenuation have been determined, the engineering design phase can be commenced. Various decisions has to be taken in this stage including the type of pond, the choice of control structures, sizes of inlet and outlet canals and any other developments necessary within the pool and temporary detention area.

\section{Is this Appropriate for Our Problems}

Most of the recent flood hazards were reported from the coastal cities such as Colombo, Galle, and Matara situated in the Wet Zone of the island. Those areas are highly populated and experience relatively high rainfalls.

Previous flood control works in those areas were confined to the strategy of embanking and channelization with or without pumping facilities for storm water evacuation. This method is not much appropriate for a developing country like ours due to following reasons.

1. Protected areas experience heavy rainfall (average annual rainfall is around $3000 \mathrm{~mm}$ ) concentrated in two monsoonal periods. Therefore the volume of surplus water to be evacuated is very high. Gravity drainage is not possible since the areas are at low elevations, sometimes below Mean Sea Level. Evacuation such large volume of water by pumping is extremely costly.

2. Income generated from the protected areas is relatively low and cost of operation and maintenance is not justifiable.

3. Construction of flood bunds is restricted due to high value of properties to be removed. Even the existing bunds in such populated areas have been encroached as shown in Figure 3

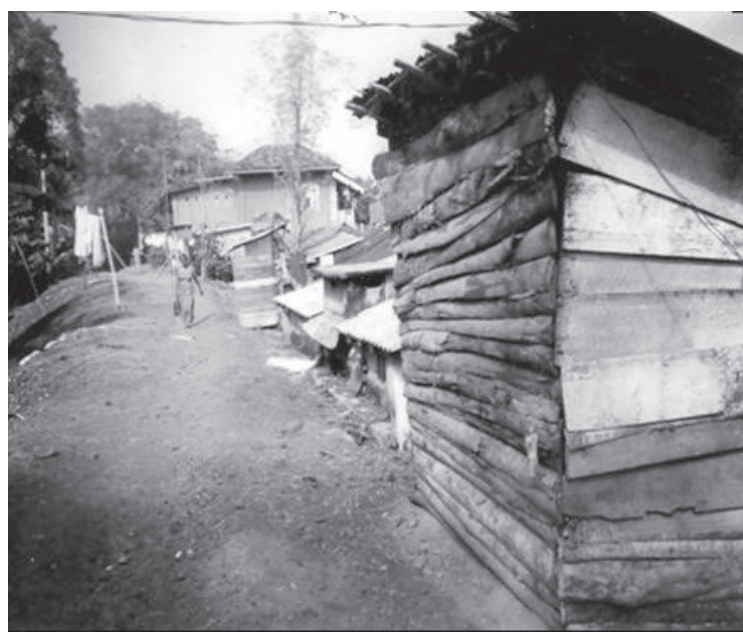

Figure 3 - Encroachments, Kelani Flood Bunds

Construction of detention reservoirs seems a sustainable and affordable solution when compared to other flood control measures. Generally the land required is available in the form of inland lakes and marshy lands (Figure 4 and 5) which cannot be used for any other economic purpose. Clearing, dredging and removal of un-authorized constructions may be required to increase the detention capacities of existing lakes and adjacent marshy lands. 
Earth moving operations are normally expensive and dredging is even more expensive. Therefore preserving existing low lands is very important. Even the function of abandoned paddy lands in controlling floods is invaluable. Therefore filling paddy fields should be avoided as far as possible.

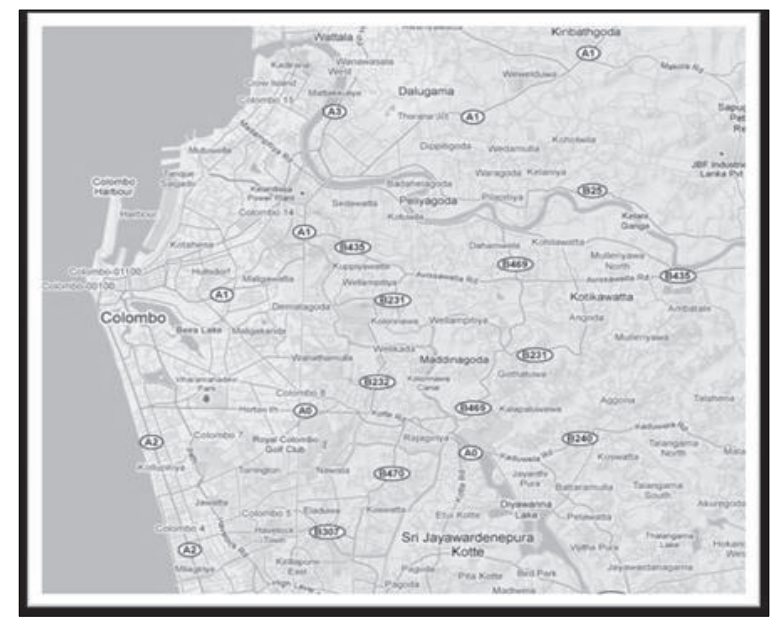

Figure 4 - Marshes and Inland Lakes (green and blue patches) in the City of Colombo

Secondly the improvement and regular maintenance of drainage canal system is extremely important. Canals should be accessible in both sides to facilitate maintenance works by machinery. Canal reservations should be demarcated and maintained properly to avoid encroachments. Flood plains and reservations stipulated for main rivers should be maintained without any construction obstructing the flow during floods.

\section{Conclusions}

Provision of detention reservoirs seems most applicable for flood mitigation in the coastal cities of our country. These detention reservoirs can serve for some other purposes such as fish breeding, nature parks, walkways and water based recreational activities. Low lands available in the form of marshes or inland lakes can economically be utilized for this purpose. Well maintained flood retarding basin is a sustainable and environment friendly solution for the problem of flooding.

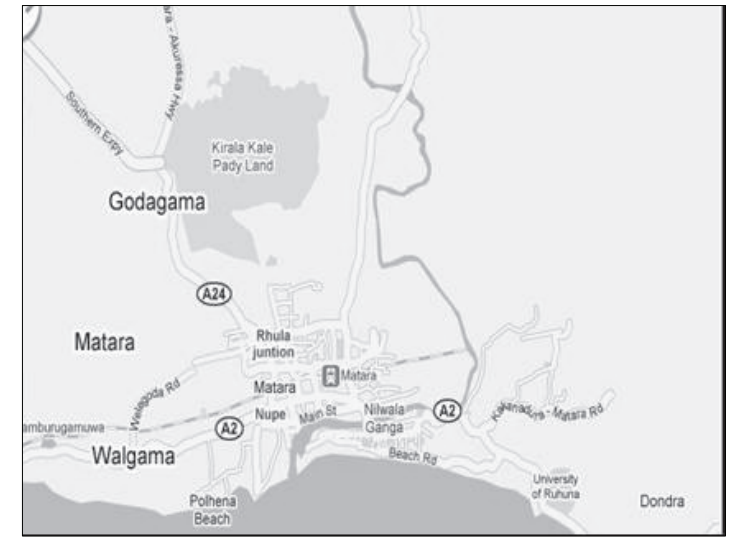

Figure 5 - Kiralakele Marsh at the city of Matara (Nilwala Basin)

\section{References}

1. Hall, M. J., Hokin, D. L., and Ellis, J. B., Design of Flood Storage Reservoirs, 1993

2 Wipple, W., Duel Purpose Detention Basins, 1979 